\title{
Phenology and population structure of the Mediterranean stripe-necked terrapin Mauremys leprosa (Schweigger, 1812) in the Reghaïa Lake (northern Algeria)
}

\author{
Badis Bakhouche1, Tiar Ghoulem²,3, Djemadi Imed ${ }^{3,4}$, Draidi Khalil ${ }^{3}$, Daniel Escoriza ${ }^{5, *}$ \\ ${ }^{1}$ Laboratoire Dynamique et Biodiversité, Université Houari Boumediene, BP 32 El Alia 16111, Algiers, Algeria. \\ ${ }^{2}$ Department of Biology, Faculty of Natural Sciences and Life, University Chadli Bendjedid, El Tarf, BP \\ 36100 El Tarf, Algeria. \\ ${ }^{3}$ Research Laboratory "Ecology of Terrestrial and Aquatic Systems", University Badji Mokhtar, Annaba, Algeria. \\ ${ }^{4}$ Food Science and Agri-Food Industries college, Ahmed Hamidouche Route de Beaulieu, El Harrach 16200, \\ Algiers, Algeria. \\ ${ }^{5}$ GRECO, Institute of Aquatic Ecology, University of Girona, 17071 Girona, Spain. \\ *Correspondence: E-mail: daniel_escoriza@hotmail.com
}

Received: 19 June 2019; returned for review: 12 July 2019; accepted 06 August 2019.

The Mediterranean stripe-necked terrapin is a freshwater turtle widely distributed in southwestern Europe and northwestern Africa, but whose natural history is little known. In this study we investigated the ecology of a population in northern Algeria (Reghaïa Lake Ramsar Reserve), with special emphasis on its phenology, demographic structure and diet, based on capture and recapture methods. Our results indicated that there is a short inactivity period in January and possibly the activity is also reduced during the month of August. The best Jolly-Seber model indicated that the population within the survey station had a minimum size of 653 specimens. The population contained a higher proportion of males $(0.68$ - 0.76) and a proportion of juveniles between 0.02 0.16 . Females were larger and relatively heavier than males. Analysis of stomach contents showed that $M$. leprosa feeds with high frequency on aquatic arthropods. Specifically, we found insects: Diptera (Chironomidae, Culicidae, Dixidae, Syrphidae), Heteroptera (Corixidae, Notonectidae) and Coleoptera (Dytiscidae), crustaceans (Branchiopoda, Ostracoda), plant matter (Typha angustifolia), fish (Gambusia holbrooki), and unidentified materials.

Key words: Algeria; demographics; diet; predation.

The Mediterranean stripe-necked terrapin Mauremys leprosa is one of two species of freshwater turtles native to northwest Africa (Schleich et al., 1996). The ecology of this species has been studied in the Iberian Peninsula, where it is described as a generalist in its use of habitats and trophic resources (SEgurado \& Figuereido, 2007; PÉrez-Santigosa et al., 2011). In Spain and Morocco, the species occupies all types of freshwater habitats, including rivers, intermittent streams, lakes, artificial reservoirs and coastal marshes (KELLER, 1997; Gómez-CANTARino \& LizAnA, 2000; Naimi et al., 2012). In Algeria, M. leprosa appears in all the north of the country, in regions with Mediterranean climate, although it also penetrates marginally in the Sahara (Doumergue, 1901; Schleich et al., 1996). Despite being relatively common 


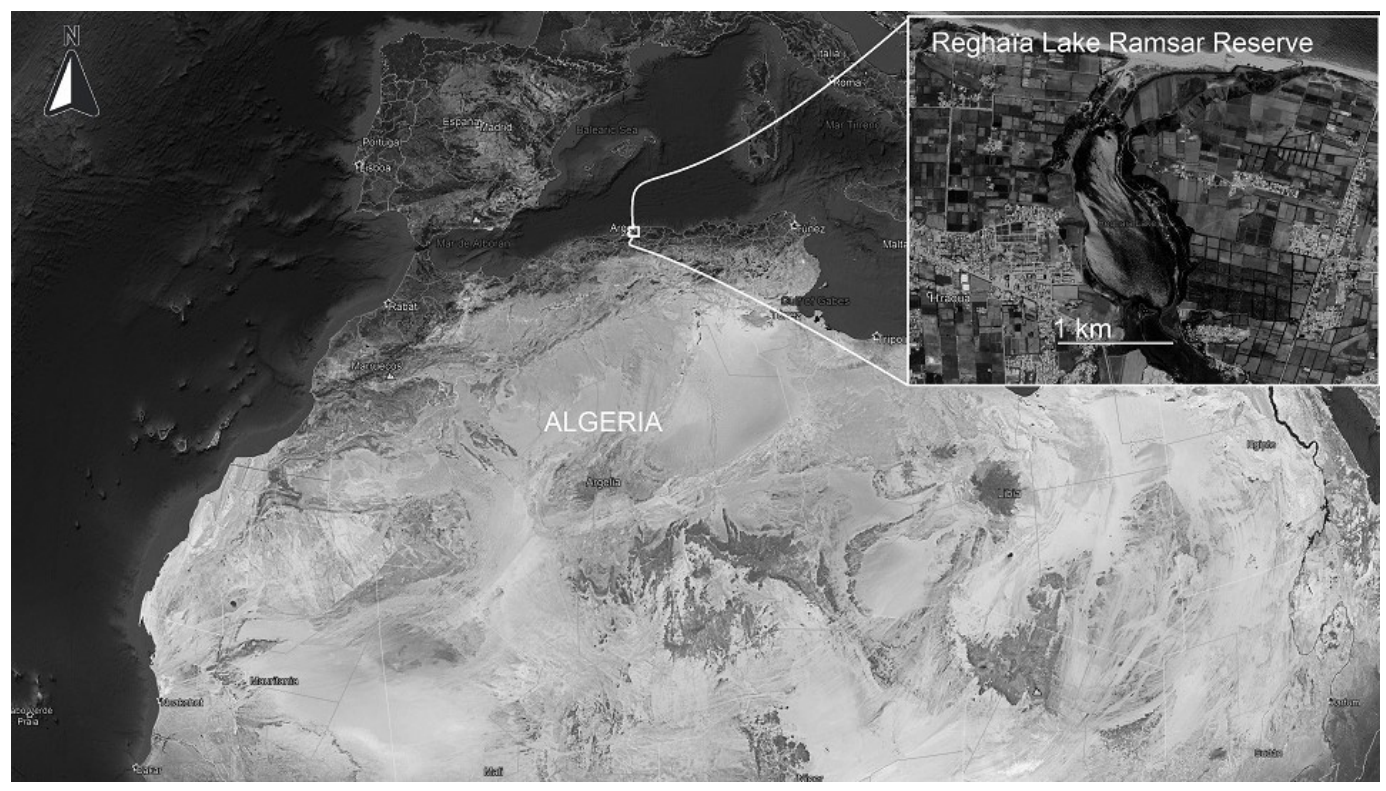

Figure 1: Map of the study region.

and widespread in much of the aquatic ecosystems of northern Algeria (EscorizA \& Ben Hassine, 2017), little is known about the natural history of this species, except for some brief, old reports (e.g. DouMERGUe, 1901). This could have negative implications for species conservation at the regional level, particularly taking into account the significant level of alteration that wetlands have suffered in northern Algeria, and other parts of the Maghreb (BRitton \& CRIvelli, 1993; DE Belair \& SAMraOUI, 1994). Improving knowledge of the natural history of the species is one of the priorities when developing management and conservation plans for the wild populations of reptiles (Cox et al., 2006). The aim of this study is to investigate the ecological requirements of this freshwater turtle, fulfilling part of the knowledge gap. Here we provided new data on the phenology, population structure, and diet of the $M$. leprosa in northern Algeria.

\section{Materials and Methods}

The Ramsar reserve of Reghaïa Lake is situated $30 \mathrm{~km}$ to the east of Algiers, close to the Mediterranean coast (Fig. 1). Ramsar reserves are wetlands of international relevance, particularly for migratory and aquatic birds (SAmraou \& SAmRAOUI, 2013). The climate of the region is of type Csa (Koppen classification), with mild winters and summers (average temperatures of January: $11.5^{\circ} \mathrm{C}$ and August: $26.1^{\circ} \mathrm{C}$; KRITIcos et al., 2012). Given the importance of this reserve for the reproduction of several threatened birds (Metna et al., 2016), surveys were carried out at single station to reduce interferences with the bird nesting activity. Turtles were captured during the day with a dipnet (LAGLER, 1943), between 11:00-16:00hr, after being detected visually around the shoreline. Additionally, we also surveyed the shoreline, to find destroyed nests or turtle remains, including 
fragments of shell or bones embedded in mammalian predator feces (ANDERSEN, 1954). Tracks and mammalian feces observed were assigned to species based on Dahlström \& Cuisin (2009). Surveys included a single monthly sampling between the years 2017-2018, including winter months.

Turtles captured were marked by notches on the marginal scutes, following a standardized code that allows individual identification (CAgle, 1939). Specimens were also examined for wounds or injuries, measured with a digital caliper (straight line carapace length; $0.01 \mathrm{~mm}$ precision), and weighted with a digital balance (0.1 mg precision). Specimens were sexed based on secondary sexual characters: the preanal width of the tail and its length (MuÑoz \& Nicolau, 2006). In our study population, those specimens with a carapace length greater than $90 \mathrm{~mm}$ were classified as adults, like other populations of M. leprosa (KeLLeR, 1997).

The diet was investigated in 32 adult and juvenile specimens captured during the second year of sampling (from April 2018 to November 2018). Stomach content was obtained by flushing (Pérez-Emán \& Paolillo, 1997). The items found in the stomach were classified into large taxonomic groups (Subphylum or Class): insects, crustaceans and fish (animal matter), and plant matter. Most of the items were very fragmented or partially digested, and identification at a finer taxonomic resolution was very difficult. However, when possible, these items were classified at finer level. Invertebrates were classified following TACHET et al. (2000).

We evaluated two demographic pa- rameters: sex ratio and proportion of juveniles (RAmos et al., 2009). The sex ratio was calculated as relative male proportion (male / male + females; Keller, 1997). Other metrics to assess the sex-ratio were proposed in turtles (Lovich \& Gibbons, 1990; Lovich, 1996; Lovich et al., 2014), but we used the relative male proportion because it facilitated the comparison with previous studies on M. leprosa. To assess whether the proportion of sexes differed from parity, we used the single proportion test (Newcombe, 1998). This test evaluated whether an observed proportion differs from a theoretical one, determining the statistical significance with the sample size (Newcombe, 1998). Capture-recapture data were used to estimate population size, using an open population Jolly-Seber model. This model assumed that the probability of capture was equivalent among the different individuals that constitute the study population (Nichols, 1992). The Jolly-Seber model estimates the probability of capture ( $p$ ) and apparent survival (phi), depending on an occasion ( $t$ ) or along the entire sampling period (.). The optimal model was determined using the Akaike Information Criterion corrected for small sample sizes (White \& Burnham, 1999). The goodness-of-fit was assessed using the RELEASE function, implemented in the MARK package (White \& Burnham, 1999). Population size was calculated based on the formula $n / \mathrm{p}$, where $n$ is the number of specimens caught on period, and $\mathrm{p}$ is the probability of capture (White \& BURNHAM, 1999).

We also were interested in evaluating possible intersexual differences in carapace length, and the body mass index 
Table 1: Survey and demographic parameters for Mauremys leprosa in the Reghaïa Lake Ramsar Reserve. Sex ratio: mean sex ratio (males/males+females) per year. Proportion of juveniles: mean relative frequency (juveniles/ total captures) per year.

\begin{tabular}{lll}
\hline & $\mathbf{2 0 1 7}$ & $\mathbf{2 0 1 8}$ \\
\hline Total unique specimens & 98 & 50 \\
Sex ratio & 0.677 & 0.762 \\
Proportion of juveniles & $2.04 \%$ & $16.00 \%$ \\
\hline
\end{tabular}

(BMI, g/cm²; Petznek et al., 2002), and seasonal variation in BMI (comparing the BMI of a given season relative to the mean BMI of others seasons). The carapace length was used to calculate a size dimorphism index $(\mathrm{SDI}=$ (mean size of largest sex / mean size of smallest sex) -1 , if females are larger; Lovich \& Gibbons, 1992). The statistical significance of these differences was assessed by Student's-t tests, conducted using the package PAST vs. 3.0 (HAMmer et al., 2001).

\section{Results}

We captured 148 specimens. The sex ratio was biased toward males (0.677), and the difference was statistically significant during the year $2017(\mathrm{z}=3.366, \mathrm{P}=0.0008)$ and $2018(z=3.677, P=0.0002)$. The proportion of juveniles was variable, ranging between 2 - 16\% (Table 1). Mutilations in the hindlimbs were observed in $14.9 \%$ of the captured specimens. Captures showed a bimodal pattern, being higher during spring, and autumn. No captures were made during January, July and August 2017 and January, February, June and August 2018, despite attempts to do so.

An open capture-recapture model was conducted using only the data obtained in 2017, because recaptures were too low in 2018. RELEASE goodness-of-fit tests indicated that the model followed the assumptions $(\chi 2=1.27, \mathrm{df}=4, P=0.87)$. The best model was phi(.) $p(t)$, in which apparent survival remained constant during the sample period but the probability of capture was time-dependent (Table 2). This model allowed an estimate of the mean probability of capture (0.089) and the minimum population size for the survey station and the year 2017 (98 / $0.15=653$ specimens).

Morphological comparisons showed that females had larger carapace sizes, and BMI than males, with SDI =0.05 (Table 3). The BMI showed intrannual variation, particularly in both sexes after winter, and in

Table 2: Jolly-Seber model candidates used to estimate population size of Mauremys leprosa in the Reghaïa Lake Ramsar Reserve. Phi = probability of apparent survival; $\mathrm{p}=$ probability of capture; $\mathrm{AIC}=$ Akaike Information Criterion corrected for small sample sizes.

\begin{tabular}{llllll}
\hline Model & Phi & p & AICc & Delta AICc & AICc Weight \\
\hline Phi(.)p(t) & 1.0 & $0.00-0.15$ & 157.54 & 0.00 & 0.79 \\
Phi(t)p(.) & $0.00-1.00$ & 0.09 & 160.45 & 2.90 & 0.18 \\
Phi(t)p(t) & $0.00-1.00$ & $0.00-0.94$ & 164.20 & 6.65 & 0.03 \\
Phi(.)p(.) & 0.05 & 0.09 & 177.61 & 20.06 & 0.00003 \\
\hline
\end{tabular}




\begin{tabular}{lllll}
\hline & Males & Females & $t$ & $\mathbf{P}$ \\
\hline$n$ & 96 & 42 & & \\
Carapace length (mm) & 174.6 & 184.1 & 1.96 & 0.051 \\
BMI & 3.68 & 4.81 & 5.98 & 0.00000002 \\
SDI & & 0.05 & & \\
\hline
\end{tabular}

Table 3: Sexual dimorphism in the population of Mauremys leprosa in the Reghaïa Lake Ramsar Reserve, assessed with t-Student tests. $n=$ number of specimens; BMI (Body Mass Index) $=\mathrm{g} / \mathrm{cm}^{2}$. SDI (Size Dimorphism Index).

Table 4: Seasonal variation of the Body Mass In$\operatorname{dex}(\mathrm{BMI})$ in a population of Mauremys leprosa in the Reghaïa Lake Ramsar Reserve, assessed with Student's t-tests. $n=$ number of specimens; $\mathrm{BMI}=\mathrm{g}$ / $\mathrm{cm}^{2}$. BMIseason $=\mathrm{BMI}$ mean seasonal value; BMI $_{\text {out }}=$ BMI mean year value (excluding $\mathrm{BMI}_{\text {season}}$ ).

\begin{tabular}{llllll}
\hline & Season & BMI $_{\text {season }}$ & BMI $_{\text {out }}$ & $\boldsymbol{t}$ & $\mathbf{P}$ \\
\hline Males & Winter & 3.82 & 3.63 & 0.86 & 0.389 \\
& Spring & 3.57 & 3.79 & -1.11 & 0.269 \\
& Summer & 3.78 & 3.66 & 0.33 & 0.740 \\
& Autumn & 3.76 & 3.66 & 0.45 & 0.652 \\
\multirow{4}{*}{ Females } & Winter & 5.34 & 4.79 & 1.24 & 0.222 \\
& Spring & 4.57 & 4.87 & -0.94 & 0.351 \\
& Summer & 4.31 & 4.89 & -0.95 & 0.346 \\
& Autumn & 4.97 & 4.73 & 0.76 & 0.453 \\
\hline
\end{tabular}

females in summer, but these differences were not statistically significant (Table 4). In the study of the diet, the stomach content of 32 specimens was examined. Of these, $59.4 \%$ were empty, with a lower proportion of empty stomachs $(28.6 \%)$ in the summer than in spring $(66.7 \%)$, and autumn (69.2\%). At our study site, M. leprosa frequently preys on aquatic insects, while other items (plant matter, fish, Crustacea) appear with lesser frequency (Table 5). The items that could be identified at a finer taxonomic resolution were fragments of Typha angustifolia (plant), fragments of crustaceans (Branchiopoda and Ostracoda), and fish (Gambusia holbrooki). We could also identify some groups of insects: Diptera, larvae of Syrphidae (genus Eristalis), larvae, pupae, and adults of Culicidae, and Dixidae, and larvae of Chironomidae; adults of aquatic insects: Corixidae
(Sigara), Dytiscidae, and Notonectidae (Anisops), and adults of terrestrial insects: Formicidae, and honey bees (genus Apis) (Fig. 2). During the terrestrial surveys around the lagoon, we found four destroyed nests, and 46 turtle shells with $52.2 \%$ showing signs of biting by carnivore mammals. Also, we found 13 scats of $\mathrm{Ca}$ nis anthus containing fragments of $M$. leprosa carapaces near the nests and shells observed.

\section{Discussion}

This study is the first to investigate the ecology of M. leprosa in Algeria, and describes its phenological cycle. Our results suggested that the Reghaïa Lake Ramsar Reserve possibly harbors a large population of this terrapin, even using conservative estimations. The population of M. leprosa from Reghaïa contained a high proportion 


\begin{tabular}{lllll}
\hline & Items & Males & Females & Juveniles \\
\hline$n$ & & 23 & 3 & 6 \\
Empty\% & & 60.9 & 33.3 & 66.7 \\
Full\% & & 39.1 & 66.7 & 33.3 \\
& Insecta larvae & 55.5 & 50.0 & 50.0 \\
& Insecta adult & 22.2 & 50.0 & 50.0 \\
& Crustacea & 22.2 & 50.0 & 50.0 \\
& Fish & 11.1 & 0.0 & 0.0 \\
& Plant & 33.3 & 50.0 & 50.0 \\
\hline
\end{tabular}

Table 5: Results of stomach flushing in 32 specimens of Mauremys lepro$s a$ in the Reghaïa Lake Ramsar Reserve. Empty\% = proportion of specimens with empty stomachs; Full\% = proportion of specimens with plant/ animal matter in the stomach; $n=$ number of specimens.

of adult individuals (84.00-97.96\%), and of these, males predominated (67.7-76.2\%). A very similar demographic structure was reported in other populations of $M$. leprosa. Keller (1997) reported a proportion of adults / sub-adults of $94.3 \%$, and a sex ratio biased toward males of $61.8 \%$, during five years of surveys in Doñana National Park (southwestern Spain). However adult sex ratios are a variable parameter in wild populations of freshwater turtles (LovicH et al., 2014). For example, ratios biased toward both males or females have been observed in the other Mediterranean species, Emys orbicularis (Mazzotti, 1995; Keller, 1997; RAmos et al., 2009). In general, those species in which there is a marked sexual dimorphism, the sex of smaller size is usually demographically dominant (LovicH et al., 2014). The analysis of sexual dimorphism showed that females are larger and have a higher relative weight than males, similar to that reported in southwestern Spain (MuÑoz \& Nicolau, 2006). Sexual dimorphism is also a variable trait in chelonians (Lovich \& Gibbons, 1992; Agha et al., 2018), and in the case of M. leprosa, it varies throughout the Moroccan range of the species. This variation is possibly attributable to local climate conditions (Lovich et al., 2010). In females, mean carapace length was similar to those described in other populations of M. leprosa (LovicH et al., 2010). However, the SDI value (0.05) was lower, because of the relatively large size of males in the Reghaïa Lake Reserve.

The capture patterns suggest intrannual variations of the activity of this species. During the months of January and August no specimens were captured, indicating a significant decrease of the species' activity during the periods of mid-winter, and mid -summer. These observations mirror those of Doumergue (1901), who indicated that the Algerian populations went into aesti-

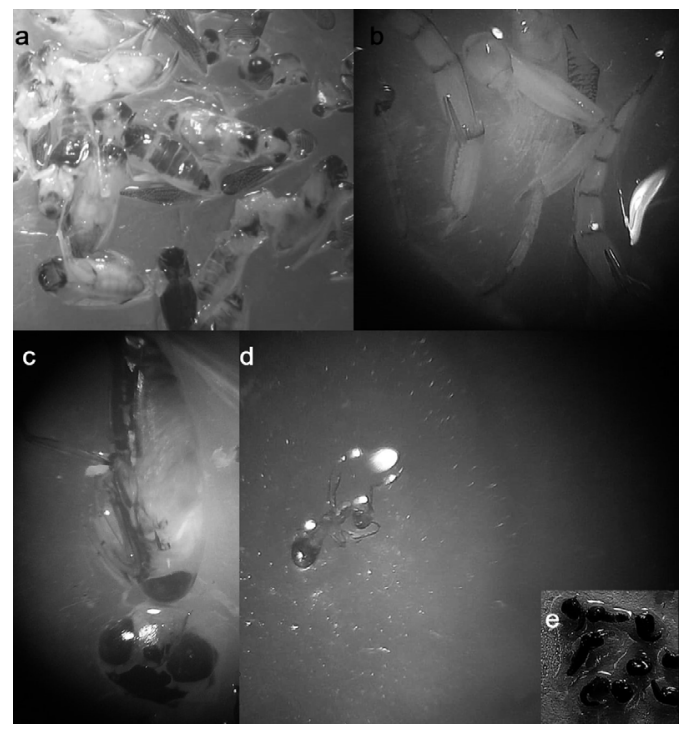

Figure 2: Items found in the stomach contents of Mauremys leprosa from the Reghaia Lake Ramsar Reserve: a) Corixidae; b) Dytiscidae; c) Notonectidae; d) Formicidae; e) $\mathrm{Cu}$ licidae. (Photos: B. Bakhouche). 


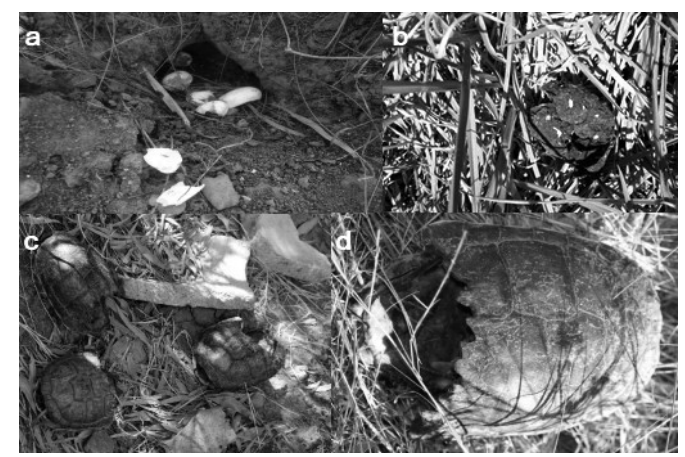

Figure 3: Examples of predation and/or scavenging of $M$. leprosa in Reghaïa: a) a nest predated by jackals (Canis anthus); b) jackal feces containing bone remains of $M$. leprosa; c and d) partially devoured carapaces (Photos: B. Bakhouche).

vation following stream desiccation. However, a large part of the marshes of Reghaïa do not experience a significant surface regression in summer. This suggests that the decrease in captures could be attributable to lesser activity, at least during the hours of the surveys (11:0016:00). The decrease of the BMI after winter in both sexes could be consequence of lower activity during this period, while the decrease observed in summer in the females (but not in the males), is possibly related to oviposition (May-July in Morocco; Naimi et al., 2012). However, these intrannual differences in the BMI did not show statistical significance, so caution is advised in associating variation in the BMI with the phenology of this population.

Diet was similar to the results of previous studies conducted on M. leprosa (e.g. Pérez-Santigosa et al., 2011). In the Reghaïa Reserve, stomach contents showed that $M$. leprosa feeds on arthropods frequently: insects (adults and larvae, mainly aquatic species but also ter- restrial), and bentho-nektonic crustaceans. However, some plant material, and occasionally fish were included. We did not detect the presence of Gastropoda in the diet, despite their observations in the diet of Spanish populations of $M$. leprosa (Pérez-Santigosa et al., 2011). Gastropods are well represented in the reserve, so their absence in the diet of turtles is perplexing. Mauremys leprosa preys on hard -bodied carnivorous insects, such as water beetles (Dytiscidae), and backswimmers (Notonectidae), as a top predator in this aquatic ecosystem.

During the shore surveys we found several damaged empty shells and bone/ carapace fragments of turtles in mammalian feces. However, it is impossible to conclude whether these specimens were depredated or died from other causes and were then scavenged. In the reserve, occasional events of 'mass mortality' of turtles were observed, and although the causes are not completely known, they could be caused by rapid salinity changes in the water (but see NAsRi et al., 2008). These episodes of mass mortality could be exploited opportunistically by predators. However, $14.9 \%$ of the specimens showed healed wounds in the limbs attributed to jackals (Canis anthus), wild boars (Sus scrofa) or brown rats (Rattus norvegicus). During the shore surveys, some destroyed nests were also found, occasionally with feces or tracks of jackals, suggesting that this canid is also a predator of $M$. leprosa nests. This behavior is known in these opportunist canids, which frequently prey on turtle nests in the Mediterranean region, including marine species (BROWN \& Macdonald, 1995). 


\section{Acknowledgement}

Permits to prospect in the field were granted by the authorities from Reghaïa Lake Ramsar Reserve. The authors thank Dr. Dani Boix (Universitat de Girona) for his helpful comments to identify aquatic invertebrates and two anonymous reviewers for their suggestions in a previous draft of this manuscript.

\section{REFERENCES}

Agha, M.; Ennen, J.R.; Nowakowski, A. J.; Lovich, J.E.; Sweat, S C. \& TodD, B.D. (2018). Macroecological patterns of sexual size dimorphism in turtles of the world. Journal of Evolutionary Biology 31: 336-345.

Andersen, J. (1954). The food of the Danish badger (Meles meles danicus Degerbol) with special reference to the summer months. Danish Review of Game Biology 3: 1-75.

Britton, R.H. \& CRIVELLI, A.J. (1993). Wetlands of southern Europe and North Africa: mediterranean wetlands, In Whigham, D. F.;

Dykyjová, D. \& Hejný, S. (eds.) Wetlands of the world: Inventory, ecology and management, Volume I. Springer. Dordrecht. Pp. 129-194.

Brown, L. \& Macdonald, D.W. (1995). Predation on green turtle Chelonia mydas nests by wild canids at Akyatan Beach, Turkey. Biological Conservation 71: 55-60.

Cagle, F.R. (1939). A system of marking turtles for future identification. Copeia 1939: 170173.

Cox, N.; Chanson, J. \& Stuart, S. (2006). The status and distribution of reptiles and amphibians of the Mediterranean Basin (No. 2). IUCN, Gland and Cambridge.

Escoriza, D. \& Ben Hassine, J. (2017). Niche separation among north-west African semiaquatic reptiles. Hydrobiologia 797: 47-56.

Dahlström, P. \& Cuisin, M. (2009). Guide des traces d'animaux: les indices de présence de la faune sauvage. Delachaux et Niestlé, Paris.
De Belair, G. \& Samraoui, B. (1994). Death of a Lake: Lac Noir in Northeastern Algeria. Environmental Conservation 21: 69-17.

Doumergue, F. (1901). Essai sur la faune erpétologique de l'Oranie: avec des tableaux analytiques et des notions pour la détermination de tous les reptiles \& batraciens du Maroc, de l'Algérie et de la Tunisie. L. Fouque, Oran.

Gómez-Cantarino, A. \& Lizana, M. (2000). Distribución y uso del hábitat de los galápagos (Mauremys leprosa y Emys orbicularis) en la provincia de Salamanca. Boletín de la Asociación Herpetológica Española 11: 4-8.

Hammer, Ø.; Harper, D.A. \& Ryan, P.D. (2001). PAST: paleontological statistics software package for education and data analysis. Palaeontologia Electronica 4: 9.

LagLER, K.F. (1943). Methods of collecting freshwater turtles. Copeia 1943: 21-25.

Lovich, J.E. (1996). Possible demographic and ecologic consequences of sex ratio manipulation in turtles. Chelonian Conservation and Biology 2: 114-117.

Lovich, J.E. \& Gibbons, J.W. (1990). Age at maturity influences adult sex ratio in the turtle Malaclemys terrapin. Oikos 59: 126-134.

Lovich, J.E. \& Gibbons, J.W. (1992). A review of techniques for quantifying sexual size dimorphism. Growth Development and Aging 56: 269-269.

Lovich, J.E.; Znari, M.; BaAmRane, M.A.A.; Naimi, M. \& Mostalih, A. (2010). Biphasic geographic variation in sexual size dimorphism of turtle (Mauremys leprosa) populations along an environmental gradient in Morocco. Chelonian Conservation and Biology 9: 45-53.

Lovich, J.E.; Gibbons, J.W. \& Agha, M. (2014). Does the timing of attainment of maturity influence sexual size dimorphism and adult sex ratio in turtles?. Biological Journal of the Linnean Society 112: 142-149.

Keller, C. (1997). Ecología de Poblaciones de Mauremys leprosa y Emys orbicularis en el Parque Nacional de Doñana. PhD. Thesis, Uni- 
versidad de Sevilla.

Kriticos, D.J.; Webber, B.L.; Leriche, A.; OtA, N.; Macadam, I.; Bathols, J. \& ScOtT, J.K. (2012). CliMond: global high-resolution historical and future scenario climate surfaces for bioclimatic modelling. Methods in Ecology and Evolution 3: 53-64.

Mazzotti, S. (1995). Population structure of Emys orbicularis in the Bardello (Po Delta, northern Italy). Amphibia-Reptilia 16: 7785.

Metna, F.; Lardjane-Hamiti, A.; Merabet, S.; Boukhemza-Zemmouri, N.; RaKem, K. \& Boukнemza, M. (2016). Ecology of the Coot's Fulica atra reproduction (Linnaeus, 1758) in the nature reserve of Lake Réghaïa (Algiers, Algeria). Zoology and Ecology 26: 166-172.

Muñoz, A. I. \& Nicolau, B. (2006). Sexual dimorphism and allometry in the stripenecked terrapin, Mauremys leprosa, in Spain. Chelonian Conservation and Biology 5: 87-92.

Naimi, M.; Znari, M., Lovich; J. E., Feddadi, Y. \& BaAmrane, M.A.A. (2012). Clutch and egg allometry of the turtle Mauremys leprosa (Chelonia: Geoemydidae) from a polluted peri-urban river in west-central Morocco. The Herpetological Journal 22: 43-49.

Nasri, H.; El Herry, S. \& Bouaïcha, N. (2008). First reported case of turtle deaths during a toxic Microcystis spp. bloom in Lake Oubeira, Algeria. Ecotoxicology and Environmental Safety 71: 535-544.

Newcombe, R.G. (1998). Two-sided confidence intervals for the single proportion: comparison of seven methods. Statistics in Medicine 17: 857-872.

Nichols, J.D. (1992). Capture-recapture models. BioScience 42: 94-102.
Pérez-Emán, J.L. \& Paolillo, A. (1997). Diet of the pelomedusid turtle Peltocephalus dumerilianus in the Venezuelan Amazon. Journal of Herpetology 31: 173-179.

Pérez-Santigosa, N.; Florencio, M.; HidalgoVila, J. \& Díaz-Paniagua, C. (2011). Does the exotic invader turtle, Trachemys scripta elegans, compete for food with coexisting native turtles?. Amphibia Reptilia 32: 167-175.

Petznek, H.; Kappler, R.; Scherthan, H.; MülLer, M.; Brem, G. \& Aigner, B. (2002). Reduced body growth and excessive incisor length in insertional mutants mapping to mouse Chromosome 13. Mammalian Genome 13: 504-509.

Ramos, S.; Franch, M.; Llorente, G.A. \& MonTORI, A. (2009). Morphometry and biological cycle of a European pond turtle (Emys orbicularis) population from north-eastern Spain. Revista Española de Herpetología 23: 117-128.

Samraoui, B. \& Samraoui, F. (2013). An ornithological survey of Algerian wetlands: Important Bird Areas, Ramsar sites and threatened species. Wild fowl 58: 71-96.

Schleich, H. H.; Kästle W. \& Kabisch K. (1996). Amphibians and Reptiles of North Africa. Koeltz Scientific Publishers, Koenigstein.

Segurado, P. \& Figueiredo, D. (2007). Coexistence of two freshwater turtle species along a Mediterranean stream: the role of spatial and temporal heterogeneity. Acta Oecologica 32: 134-144.

Tachet, H.; Richoux, P.; Bournaud, M. \& Usseglio-Polatera, P. (2000). Invertébrés d'eau douce: Systématique, biologie, écologie. CNRS, Paris.

White, G.C. \& Burnham, K.P. (1999). Program MARK: survival estimation from populations of marked animals. Bird Study 46: 120139. 